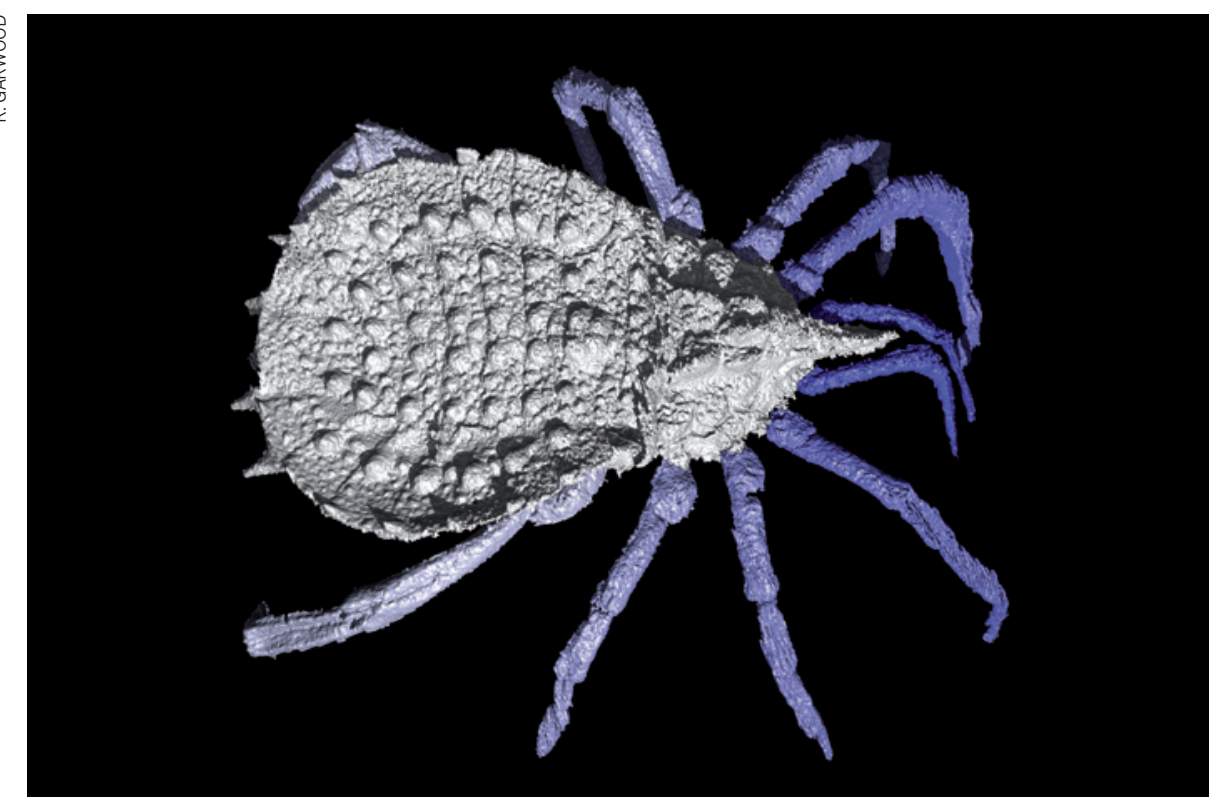

Online archives can host 3D scans of fossils, such as the arachnid Eophrynus prestvicii (above).

\title{
PALAEONTOLOGY
}

\section{Fossil data enter the web period}

\section{Palaeontologists call for more sharing of raw information.}

\section{BY EWEN CALLAWAY}

$\mathrm{W}$

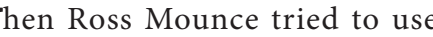
measurements of a fossilized feathered theropod dinosaur in his research, he hit a big stumbling block. A data table in the paper describing the dinosaur contained a formatting error that prevented Mounce from working out the creature's relationship to other dinosaurs, and the paper's senior author ignored repeated e-mail requests for the original file.

Mounce, who is studying for a PhD in evolution at the University of Bath, UK, eventually got the file after the journal's editor intervened. Now Mounce is leading a campaign to avoid such situations by making it standard practice for palaeontologists to upload the raw data behind their papers into online repositories common practice in other disciplines but rare in palaeontology. The call has drawn a mixture of support and dismay, but a sea change may already be under way: several palaeontology journals have recently rolled out digital-archiving policies that align with Mounce's goal.

Palaeontologists calling for better digital record-keeping and data sharing say that the move will not only spare scientists the trouble of tracking down information about fossils, but will also underpin future studies using the data in ways that are not possible today. "I think that is far and away the biggest plus," says Peter Wagner, curator of palaeozoic molluscs at the US National Museum of Natural History (NMNH) in Washington DC, who backs the campaign.

Public repositories already aid data sharing in other fields. Genbank (www.ncbi.nlm. nih.gov/genbank), a database run by the US National Center for Biotechnology Information in Bethesda, Maryland, makes more than 100 million genetic sequences freely available, and most journals demand that scientists publishing in their pages add their data to it.

Similar databases do exist for palaeontologists. Morphobank (morphobank.org), for example, logs detailed fossil images, including three-dimensional computed tomography scans. Another repository, Treebase (treebase. org), collects the phylogenetic trees that show evolutionary relationships between species. But journals do not compel researchers to add their data to these systems, and Mounce along with almost 150 signatories to an open letter (supportpalaeodataarchiving.co.uk) thinks that they should.
Some scientists are concerned that disclosing key data such as detailed geographical information about fossil discoveries would feed the illicit fossil trade. "The Burgess Shale is a case in point. It's a well known locality and it's pillaged to death," says Jonathan Antcliffe, a palaeobiologist at the University of Bristol, UK, referring to a rich trove of Cambrian fossils in the Canadian Rocky Mountains. Some countries, including the United States, make it illegal to publicly disclose fossil sites on public lands.

Antcliffe is also concerned that mandatory data archiving could discourage scientists from publishing progress reports on long-term projects, fearing that rivals will use the raw data to scoop them. He adds that graduate students, who might take more time than experienced palaeontologists to turn research into papers, would be especially vulnerable.

Tensions between scientists who discover new fossils and those who analyse and synthesize their finds are not new, says Mike Benton, a vertebrate palaeontologist at the University of Bristol. For example, Jack Sepkoski of the University of Chicago, Illinois, who in the 1970s and 1980s studied mass extinctions in the global fossil record, faced criticisms for repurposing other scientists' field work. But, says Benton, "if you wanted to keep it secret, you shouldn't have published it".

Whether palaeontologists are ready for mandatory digital archiving or not, the field seems to be going in that direction. Propelled in part by data-sharing edicts from funding agencies such as the US National Science Foundation, the Journal of Vertebrate Paleontology announced in January that it would require authors to post raw data files on its website (A. Berta and P. M. Barrett J. Vert. Paleontol. 31, 1; 2011). It is also considering mandating storage in public repositories such as Morphobank. Meanwhile, the Paleontological Society in Boulder, Colorado, which publishes Paleobiology and the Journal of Paleontology, last month decided to archive data from its papers using a repository called Dryad (datadryad.org). "My only concern is that archiving so far is an unfunded mandate," says Philip Gingerich, the society's president. "Archiving could easily consume an entire research budget."

Brian Huber, curator of planktic foraminifera at the NMNH and co-editor of the Journal of Paleontology, says that he too was wary of the costs of digital archiving, but has come around to the idea. "This is the way of the future, and the society decided we've got to lead on this instead of being too conservative." -

\section{CORRECTION}

The News story 'Bulgarian funding agency accused of poor practice' (Nature 472, 19; 2011) wrongly stated that 250 million leva is equivalent to US\$181,000. It should have been US\$181 million. 